\title{
Forecasting the strength properties of the large diameter polymer rebar based on the experimental analysis of its structure
}

\author{
Andrey Benin ${ }^{1, *}$, Artem Semenov ${ }^{2}$, Maxim Lobachev ${ }^{3}$ and Galina Bogdanova ${ }^{4}$ \\ ${ }^{1}$ Emperor Alexander I St. Petersburg State Transport University, Mechanical laboratory named prof. \\ N.A. Belelubsky, 190031 St. Petersburg, Russia \\ ${ }^{2}$ Technische Universität Dresden (TUD), Institute of Solid Mechanics, 01062 Dresden, Germany \\ ${ }^{3}$ Peter the Great St. Petersburg Polytechnic University, Institute of Applied Mathematics and \\ Mechanics, 195251 St. Petersburg, Russia \\ ${ }^{4}$ Emperor Alexander I St. Petersburg State Transport University, Buildings Department, 190031 St. \\ Petersburg, Russia
}

\begin{abstract}
Fiber reinforced plastic bar (FRP-rebar) is a two-component material consisting of polymer matrix (resin) and reinforcing filler (roving). Large-scale implementation of FRP-rebar and improvement of its manufacturing process have resulted in larger bar diameters. However, it is extremely complicated or even impossible to experimentally determine the mechanical properties of this kind of rebar when using standard testing machines. The reason for this is the low cross-direction strength of the rebar. The purpose of the research is to determine the elastic and strength properties of large diameter FRP-rebar by means of finite-element simulation as well as to analyze the influence of the components' mass fractions and grooving on the mechanical properties being studied. In order to specify the parameters of the FE simulation model the authors performed some supplementary tests aimed at determining the structure of the fiber. A comparative study of the obtained numerical results against the experimental data is presented in the paper.
\end{abstract}

\section{Introduction}

Fiber reinforced plastic bar (FRP-rebar) is a two-component material used for the purpose of reinforcing concrete structures and serving as a modern alternative to traditional metal reinforcement bars.

FRP-rebar consists of polymer matrix, which is a structure formed by solidified thermosetting resin (mainly by polyethylene terephthalate (PET)) and ensuring the matrix integrity, and of reinforcing filler (roving), which is a high-strength material linked together with the resin before solidifying in order to improve physical and mechanical properties of

\footnotetext{
"Corresponding author: benin.andrey@mail.ru
} 
the polymer compound. As a filler one usually applies roving consisting of glass or basalt fiber, or (rarely) of carbon fiber.

FRP-rebar has many benefits, the low specific weight, easy transportation, high tensile strength, resistance to corrosion and oxidation, and low heat conductivity being among them. Its drawbacks are low heat resistance and comparatively low elastic modulus (approx. $50 \mathrm{GPa}$ for FRP-rebar). The latter results in the fact that a structure reinforced with FRP-rebar has less stiffness than a reinforced concrete structure, which limits its application in construction.

Numerous norms and standards have recently been elaborated and put into practice in different countries (Table 1). The application of these documents and improvement of the FRP-rebar manufacturing process have led to a significant expansion of FRP-rebar use and hence to the growth of its production as well as a change in the range of available bars - the latter being made of larger diameters (18 $\mathrm{mm}$ and larger). However, due to the low FRPrebar cross-direction strength (the reinforcing fiber has longitudinal position in the material) it is quite challenging to define the large diameter rebar mechanical properties in an experimental way [1]. Thus, the issues of forecasting large diameter FRP-rebar mechanical properties (tensile strength and elastic modulus) as well as identifying its best composition and structure aimed at maintaining the setpoint values of stiffness and strength still stay unresolved.

Table 1. List of norms and standards covering the use of glass fiber reinforcement bars (Source, https://practeco.ru/tekhnologiya/prochnost-epoksidnoj-smoly.html).

\begin{tabular}{|c|c|c|}
\hline Country & Document No. & Document Title \\
\hline \multirow{5}{*}{ Russia } & GOST 31938-2012 & $\begin{array}{l}\text { Polymer composite reinforcement bars for reinforcing concrete } \\
\text { structures }\end{array}$ \\
\hline & SP 405.1325800.2018 & $\begin{array}{l}\text { Concrete structures with non-metallic fiber and polymer } \\
\text { reinforcement bars. Design regulations }\end{array}$ \\
\hline & SP 164.1325800 .2014 & $\begin{array}{l}\text { Reinforcing concrete structures with composite materials. } \\
\text { Design regulations }\end{array}$ \\
\hline & $\begin{array}{c}\text { STO } \\
83269053-001-2010\end{array}$ & $\begin{array}{l}\text { Application of non-metallic composite reinforcement bars with } \\
\text { deformed section in transport construction }\end{array}$ \\
\hline & TR 013-1-14 & $\begin{array}{l}\text { Application of composite reinforcement bars. Technical } \\
\text { recommendations for application of non-metallic reinforcement } \\
\text { bars in concrete structures }\end{array}$ \\
\hline \multirow[t]{2}{*}{ Canada } & CAN/CSA-S806-02 & $\begin{array}{l}\text { Design and Construction of Building Components with Fibre- } \\
\text { Reinforced Polymers }\end{array}$ \\
\hline & CAN/CSA-S6-06 & Canadian Highway Bridge Design Code \\
\hline \multirow{3}{*}{ USA } & 440.1R-06 & $\begin{array}{l}\text { Guide for the Design and Construction of Structural Concrete } \\
\text { Reinforced with FRP Bars }\end{array}$ \\
\hline & 440.2R-08 & $\begin{array}{l}\text { Guide for the Design and Construction of Externally Bonded } \\
\text { FRP Systems for Strengthening Concrete Structures }\end{array}$ \\
\hline & 440.3R-04 & $\begin{array}{l}\text { Guide Test Methods for Fiber-Reinforced Polymers (FRPs) for } \\
\text { Reinforcing or Strengthening Concrete Structures. }\end{array}$ \\
\hline \multirow{2}{*}{ Japan } & & $\begin{array}{l}\text { Recommendation For Design And Construction Of Concrete } \\
\text { Structures Using Continuous Fiber Reinforcing Materials, } \\
\text { Research Committee on Continuous Fiber Reinforcing Materials }\end{array}$ \\
\hline & & $\begin{array}{l}\text { Seismic Retrofiting Design and Construction Guidelines for } \\
\text { Existing Reinforced Concrete (RC) Buildings with FRP } \\
\text { Materials }\end{array}$ \\
\hline Europe & FIP Task Group 9.3 & FRP reinforcement in RC structures \\
\hline
\end{tabular}




\section{Formulation of the problem}

The standards in force (GOST 32492-2015 Fiber-reinforced polymer bar for concrete reinforcement. Determination of physical-mechanical properties) recommend to use samples with reduced cross-section when performing an axial tension test aimed at determining the large diameter FRP-rebar strength properties. In the middle of the sample a kind of neck is made (Fig. 1, a) differing it from a standard sample (Fig. 1, b). Hence, due to the nature of composite material, the manufacturing of samples becomes much more labor-intensive (and thus, more expensive), and the probability of undercutting the fiber, which makes the neck asymmetrical, grows dramatically. On the other hand, if using standard samples, a need appears to fill sockets of very big length and thickness (Fig. 2, a); otherwise, the sample collapses due to the cut-off of the winding (Fig. 2, b) or due to the collapse of the socket itself, which in both cases results in a failure to determine the strength properties.

a)

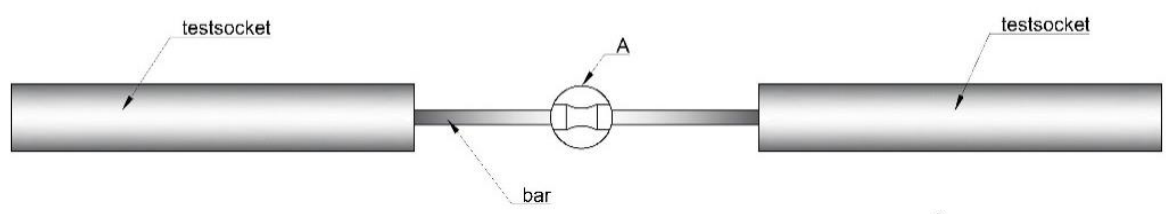

A

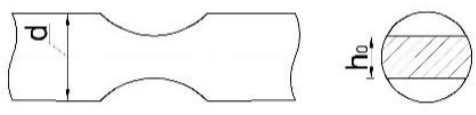

b)

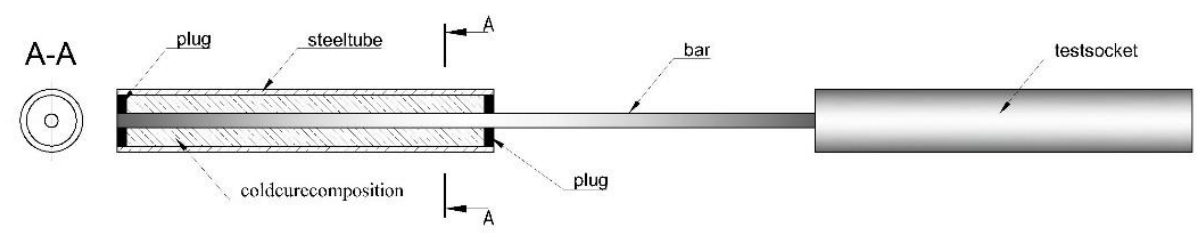

Fig. 1. FRP-rebar sample types used in the axial tension tests: a) sample with a flat neck; b) standard test sample.

Together with determining strength properties based on GOST 31938-2012 «Polymer composite reinforcement bars for reinforcing concrete structures. General specifications» it is necessary to experimentally identify the mass fractions of composite components. In particular, the FRP-rebar shall contain continuous reinforcement filler with a mass fraction of not less than $75 \%$. These experiments only require availability of specialized equipment and are not technically complicated. However, the obtained values of the composite components' mass fractions can be used for the prediction mechanical properties of the material.

Thus, the task of this research is prediction the elastic and mechanical strength properties of large diameter FRP-rebar using additional experimental information (determination of mass fractions of components) and finite-element simulation. 
a)

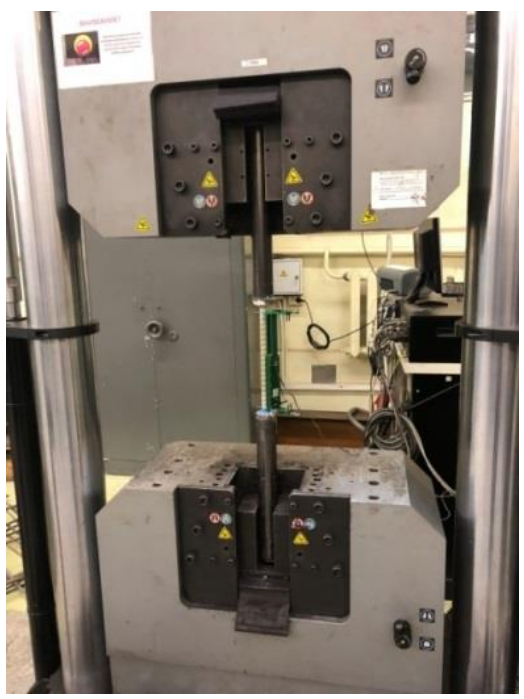

b)

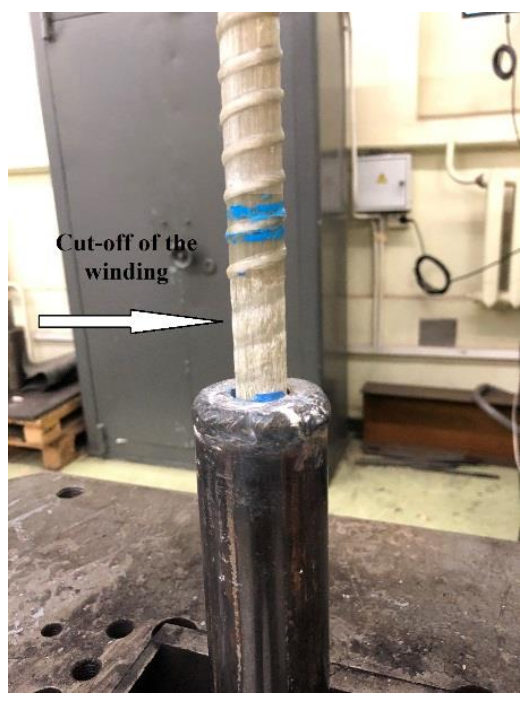

Fig. 2. Testing samples of large diameter composite rebar: a) the sample general view; b) the sample collapse due to the cut-off of the winding.

\section{Experimental studies}

The experiments were carried out on the basis of $8 \mathrm{~mm}$ diameter rebar (full program) and $18 \mathrm{~mm}$ diameter rebar (reduced program). The results of the $8 \mathrm{~mm}$ diameter rebar tests were later taken as a reference for the finite-element model verification. The plan of the experiment is shown in Table 2.

Table 2. Plan of the experiment.

\begin{tabular}{|l|c|c|}
\hline \multirow{2}{*}{\multicolumn{1}{|c|}{ Property }} & \multicolumn{2}{|c|}{ Diameter of rebar } \\
\cline { 2 - 3 } & $8 \mathrm{~mm}$ & $18 \mathrm{~mm}$ \\
\hline Nominal diameter & + & + \\
\hline Mass fraction of fiber & + & + \\
\hline Tensile strength & + & - \\
\hline Elastic modulus & + & + \\
\hline
\end{tabular}

Experiments were carried out in the Mechanical Laboratory named after prof. N.A. Belelubsky, Emperor Alexander I St. Petersburg State Transport University, according to GOST 31938-2012 and 32492-2015. The results of the experiment are shown in the Table 3.

Table 3. Results of the experiment.

\begin{tabular}{|l|c|c|c|c|}
\hline \multirow{2}{*}{ Property } & \multirow{2}{*}{$\begin{array}{c}\text { Unit of } \\
\end{array}$} & \multirow{2}{*}{$\begin{array}{c}\text { Standard, } \\
\text { measurement }\end{array}$} & \multicolumn{2}{c|}{ Diameter of rebar } \\
\cline { 4 - 5 } & $\mathrm{mm}$ & - & $8 \mathrm{~mm}$ & $18 \mathrm{~mm}$ \\
\hline Nominal diameter & $\%$ & 75 & 79.80 & 18.52 \\
\hline Mass fraction of fiber & $\%$ & 800 & 943 & - \\
\hline Tensile strength & $\mathrm{MPa}$ & 50 & 50.85 & 52.40 \\
\hline Elastic modulus & $\mathrm{GPa}$ & &
\end{tabular}




\section{Analytical evaluations}

Due to the unidirectional kind of rebar fiber reinforcement the initial calculation of the fiber composite elastic modulus was performed by mixture rule. For the composite material the upper (Voigt (1) [2]) and the lower (Reuss (2) [3]) Hill estimators of the FRP-rebar elastic modulus were obtained

$$
\begin{aligned}
& E=\frac{V_{a}}{V_{a}+V_{m}} E_{a}+\frac{V_{m}}{V_{a}+V_{m}} E_{m} \\
& \frac{1}{E}=\frac{V_{a}}{V_{a}+V_{m}} \frac{1}{E_{a}}+\frac{V_{\mathrm{M}}}{V_{a}+V_{m}} \frac{1}{E_{m}}
\end{aligned}
$$

where $V_{m}, E_{m}$ are the volume and the elastic modulus of the matrix (thermosetting resin),

$V_{a}, E_{a}$ are the volume and the elastic modulus of the reinforcing filler (glass fiber).

Equations (1) and (2) can be presented through the volume fractions of the composite components

$$
\begin{gathered}
E=\tilde{V}_{a} \cdot E_{a}+\tilde{V}_{m} \cdot E_{m} \\
\frac{1}{E}=\tilde{V}_{a} \cdot \frac{1}{E_{a}}+\tilde{V}_{m} \cdot \frac{1}{E_{m}}
\end{gathered}
$$

The volume fraction of the reinforcing glass fiber in the composite material is determined by formula

$$
\tilde{V}_{a}=\frac{V_{a}}{V}=\frac{\tilde{C}_{a} \cdot \rho_{m}}{\tilde{C}_{a} \cdot \rho_{m}+\tilde{C}_{m} \cdot \rho_{a}}
$$

where $V$ is the total volume of composite,

$\tilde{C}_{a}, \tilde{C}_{m}$ are glass fiber and matrix mass fractions in the composite (respectively),

$\rho_{a}, \rho_{m}$ are the values of glass fiber and matrix density (respectively).

In calculations we applied the values of composite components' properties provided by the FRP-rebar manufacturers. These are given in Table 4 [4].

Table 4. General mechanical properties of two types of glass fiber and PET.

\begin{tabular}{|l|c|c|c|c|}
\hline \multirow{2}{*}{ Property } & \multirow{2}{*}{$\begin{array}{c}\text { Units of } \\
\text { measurement }\end{array}$} & \multicolumn{2}{|c|}{ Type of glass fiber } & \multirow{2}{*}{ PET } \\
\cline { 3 - 4 } & & $\mathrm{E}$ & $\mathrm{S}$ & \\
\hline Density & $\mathrm{g} / \mathrm{cm}^{3}$ & 2.54 & 2.40 to 2.58 & 1.38 to 1.40 \\
\hline Pristine fiber strength & $\mathrm{MPa}$ & 3500 & 4600 to 4900 & - \\
\hline Elastic modulus & $\mathrm{GPa}$ & 73 & 82 to 93 & 2.5 to 3 \\
\hline Resin tensile strength & $\mathrm{MPa}$ & - & - & 40 to 140 \\
\hline Elongation at break & $\%$ & 4.8 & 5.4 & 2 to 4 \\
\hline
\end{tabular}

Thus, in calculations we assumed that $E_{\mathrm{A}}=73 \mathrm{GPa}$ and $E_{\mathrm{M}}=3 \mathrm{GPa}$. The upper and lower boundaries of the elastic modulus obtained for FRP-rebar by equations (1) and (2) are shown in the diagrams depending on the volume of reinforcing filler (Fig. 3). 


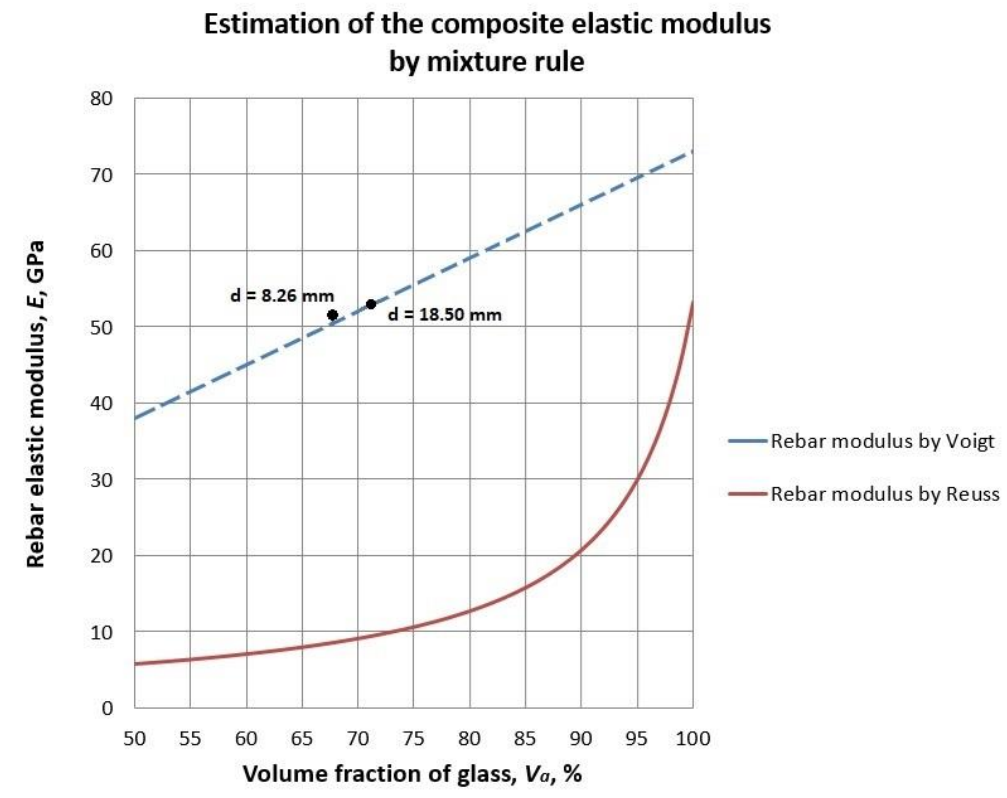

Fig. 3. Diagram showing the ratio of the composite elastic modulus and the volume fraction of the reinforcing material.

Points in the diagram (Fig. 3) show the values of the elastic modulus obtained experimentally for bars of $8.26 \mathrm{~mm}$ and $18.50 \mathrm{~mm}$ nominal diameter accounting for the exact values of reinforcing fiber volume fractions (67.8\% and $70.9 \%$ respectively). Thus, it is proved that the use of the upper bound estimation of the elastic modulus (Voigt formula (1)) correlate well with the experimental data.

Similar equations for calculating the upper and lower boundaries of tensile strength by mixture rule are as follows

$$
\begin{aligned}
& \sigma=\tilde{V}_{a} \cdot \sigma_{a}+\tilde{V}_{m} \cdot \sigma_{m} \\
& \frac{1}{\sigma}=\tilde{V}_{a} \cdot \frac{1}{\sigma_{a}}+\tilde{V}_{m} \cdot \frac{1}{\sigma_{m}}
\end{aligned}
$$

The results of the calculation (with respect to the input data given in Table 4) are shown in Fig. 4.

Once the results of experimental and analytical studies were compared, a significant difference was detected between the values obtained. As far as some analogous experimental data are concerned (source, https://www.owenscorning.com/composites), one can notice that the application of linear approximations, which are similar to those used for estimating the upper bound of the fiber composite elastic modulus (1), leads to a critical departure of the analytical values of limit stress (short-term tensile strength) from the experimental data. The actual FRP-rebar static strength appears to be lower than the estimators calculated by mixture rule (6). The reasons for this rest on a number of factors associated with non-homogeneity and multiple stages of the FRP-rebar fracture process as well as with the peculiarities of its manufacturing technology. Among these reasons are the following: action of the fiber initial stress that appears in the manufacturing process when the composite is cooling down due to the difference between the fiber and the matrix coefficients of thermal expansion; development of microcracks on the fiber surface; statistic variety of the fiber geometrical parameters resulting (in case of their abundance) in a 
reduction of strength (the weakest-link model used for estimating reliability) and in a scale factor effect; clustering of collapse areas caused by the fact that FRP-rebar is initially manufactured by banding fiber in a strand; non-homogeneity of stress fields in undamaged fiber resulting from the collapse of the matrix and/or separate fibers.

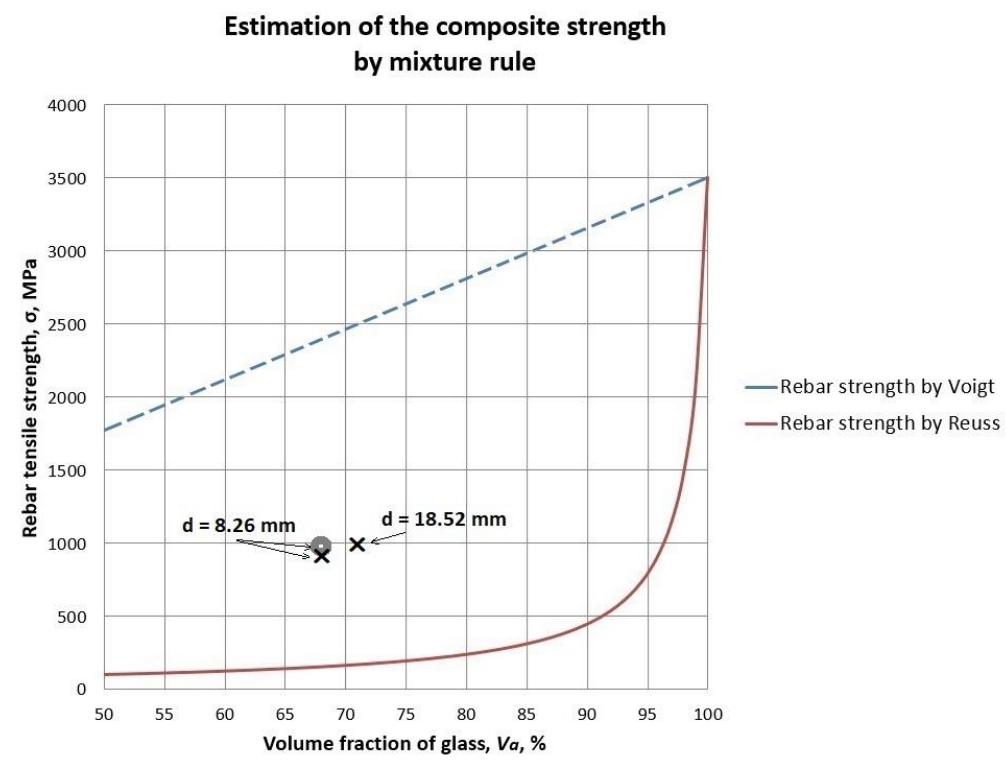

Fig. 4. Diagram showing the ratio of the composite tensile strength and the volume fraction of reinforcing material ( $\mathbf{O}$ - experimentally; $\mathbf{X}$ - by means of finite-element simulation).

A fiber breakout causes a local increase in stress in the adjacent fibers as well as the fracture of the matrix in the proximity of breakout, and a failure of the interface links between strands, which leads to a reduction of the FRP-rebar total strength. In this case the topology of the elements parallel connection gets broken, and the linear relationship (6) based on the idea of the composite components' parallel connection doesn't allow for the description of the FRP-rebar tensile strength dependency on the glass fiber volume fraction.

The abovementioned microstructural features of the FRP-rebar collapse process can be directly accounted for in the strength estimation by means of forward mathematical simulation based on the multiple-option computational experiments using finite-element solutions.

\section{Finite-element simulation}

To predict the rebar tensile strength the stress-strain behavior of a representative volume of FRP-rebar was analyzed. Determination of the effective elastic moduli was performed on the basis of the finite-element homogenization method [5, 6]. In computational experiments the finite-element software ANSYS v.19.2 was used. The finite-element model of the representative elementary volume element for FRP-rebar accounts for the individual geometries of all fibers. In the finite-element model we used SOLID 185 3D hexagonal isoparametric finite elements based on the finite quadratic approximations of the displacement fields. Two 3D finite-element models of different single profile sections of the rebar (length: $15 \mathrm{~mm}$ ) is shown in Fig. 5, and its properties are given in Table 5. The 
volumetric content of the isotropic component shares presented in the models meets the experimental requirements.
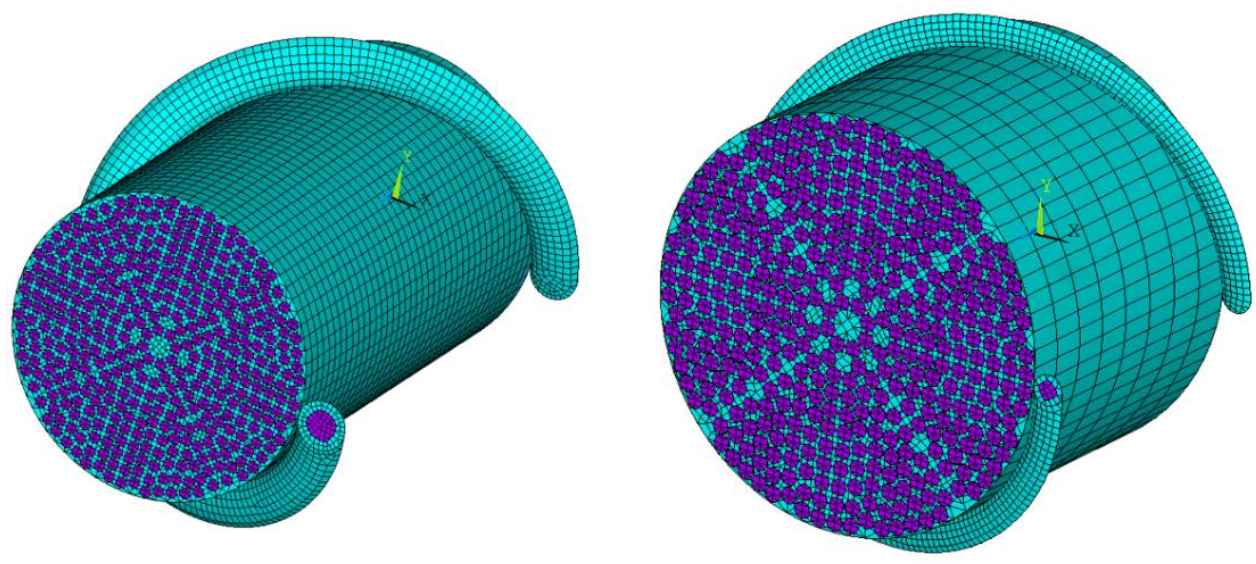

Fig. 5. FRP-rebar finite-element models.

Table 5. Parameters of finite-element model and solution.

\begin{tabular}{|l|c|c|}
\hline Nominal diameter, $\mathrm{mm}$ & 8.26 & 18.5 \\
\hline Number of nodes & 201453 & 168036 \\
\hline Number of elements & 401423 & 98601 \\
\hline Number of degrees of freedom & 604359 & 504108 \\
\hline $\begin{array}{l}\text { Method of solving the contact } \\
\text { problem }\end{array}$ & \multicolumn{2}{|c|}{ MPC algorithm } \\
\hline
\end{tabular}

In the simulation kinematic boundary conditions were applied in the plane of symmetry (plane of endface clamping) and also static boundary conditions were applied to the front face (axial tension force). As a result we can see two different reactions of two samples after applying the same force. The value of the matching averaged component of the stress tensor for fiber for the sample with less diameter is higher than the value of the big one, Fig. 6.
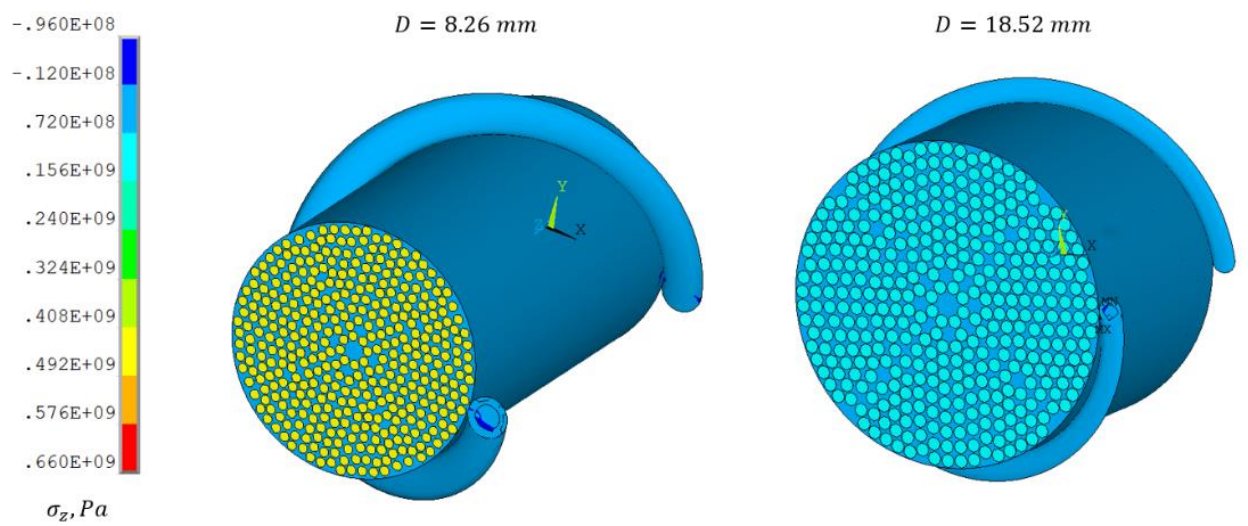

Fig. 6. Distribution of the tensile stress component in two models. 
Analysis of the FRP-rebar failure process was based on the local strength approach that implied comparison of extremal values of stress-strain state characteristics of individual composite components with their strength parameters. It was assumed that mechanisms of each component fracture were of brittle type, so, as a criterion of fracture we took the condition when the maximum principal value of the stress tensor reached the value of tensile strength (see Table 4) of the corresponding composite component.

Comparison of the finite-element simulation results with the results of the experimental data (Fig. 4 and 5) proved a high level of correlation for the FRP-rebar $8.26 \mathrm{~mm}$ diameter sample and helped to forecast tensile strength for the FRP-rebar $18.52 \mathrm{~mm}$ diameter sample.

\section{Conclusions}

1. If direct tests are impossible, one can use formula (1) (the upper bound of the composite elastic modulus by Voigt) in order to determine the initial elastic modulus of large diameter FRP-rebar samples. However, it is necessary to carry out preliminary experiments and determine the volume fractions of composite components.

2. In the analysis of limit stress, linear approximation (6) applied for the purpose of estimating the fiber composite elastic modulus (1) leads to a significant departure from experimental data caused by the fact that many factors are not accounted for, especially those associated with non-homogeneity and multiple stages of the FRP-rebar collapse process as well as with the peculiarities of its manufacturing technology.

3. An algorithm is proposed to identify FRP-rebar tensile strength based on the experimental determination of the composite components' volume fractions and on the forward mathematical simulation of the collapse process of representative volume of FRPrebar accounting for the microstructure, the initial technological micro-stress, and the analysis of the fiber breakout process evolution based on the finite-element method.

\section{References}

1. A. Benin, G. Bogdanova, S. Semenov, Appl Mech Mater, 617, 215 (2014)

2. A. Reuss, Z. Angew. Math. und Mech, 9(1), 49 (1929)

3. W. Voigt, Lehrbuch der Kristallphysik (Teubner, Berlin, 1928)

4. A.V. Shirko, A.V. Spiglazov, A.N. Kamlyuk, A.S. Drobysh, J. Eng. Phys. Thermophys, 90(3), 705 (2017)

5. V. I. Gorbachev, Moscow Univ. Mech. Bull., 71(6), 137 (2016)

6. V. I. Gorbachev, A. N. Emel'yanov, Mech Sol, 49, 73 (2014) 